\title{
UJI AKTIFITAS EKSTRAK METANOL BINTANG LAUT (Asterias forbesi) TERHADAP PERTUMBUHAN JAMUR Aspergillus sp. DAN Candida albicans SECARA In Vitro
}

\author{
Siti Juariah $^{1^{*}}$, Febi Ramadhani ${ }^{2}$ \\ ${ }^{1}$ Akademi Analis Kesehatan Fajar Pekanbaru \\ ${ }^{2}$ Mahasiswi Akademi Analis Kesehatan Fajar Pekanbaru \\ *E-mail: siti.juariah1005@gmail.com
}

\begin{abstract}
ABSTRAK
Masalah kesehatan sering menimbulkan berbagai macam penyakit, beberapa penyakit banyak disebabkan oleh makanan yang terkontaminasi oleh jamur patogen. Beraneka ragam obat saat ini banyak mempunyai efek samping yang berbahaya bagi kesehatan. Pengobatan secara alami yang tidak menimbulkan dampak yang buruk bagi kesehatan manusia merupakan solusi untuk mengurangi efek samping salah satu yang berasal dari laut yaitu bintang laut (Asterias forbesi). Metode yang digunakan yaitu experimental laboratory. Tujuan dari penelitian ini untuk mengetahui zona hambat dan konsentrasi terbaik ekstrak metanol bintang laut (Asterias forbesi) terhadap pertumbuhan jamur Aspergillus sp. dan Candida albicans. Setelah dilakukan penelitian tentang uji efektifitas ekstrak metanol bintang laut (Asterias forbesi) terhadap pertumbuhan Aspergillus sp dan Candida albicans maka diperoleh bahwa ekstrak metanol Bintang Laut (Asterias forbesi) dapat menghambat pertumbuhan jamur Aspergilus sp. dan Candida albicans. Ekstrak metanol bintang laut $100 \%$ mampu menghambat pertumbuhan jamur Aspergilus sp. sebesar 0,88\% dan Candida albicans sebesar $0,49 \%$, ekstrak metanol $75 \%$ mampu menghasilkan diameter zona hambat sebesar $0,6 \%$ terhadap jamur Aspergilus sp dan 0,44\% terhadap jamur Candida albicans. Pada konsentrasi 50\% mampu menghambat pertumbuhan jamur Aspergilus sp sebesar 0,66\% dan 0,42 pada jamur Candida albicans. Sedangkan pada konsentrasi terkecil yakni 25\% menghasilkan kemampuan penghambatan yang lebih kecil yakni $64 \%$ dan 0,38\% terhadap jamur Candida albicans.
\end{abstract}

Kata Kunci: Bintang Laut (Asterias forbesi), Aspergillus sp. dan Candida albicans

\begin{abstract}
Health problems often cause various diseases, some diseases are caused by food contaminated of pathogenic fungi. A wide assortment of many current drugs have side effects that are harmful. Natural treatment that does not cause an adverse impact on human health is a solution to reduce the side effects, the starfish (Asterias forbesi). The method used is experimental laboratory. The purpose of this study to determine the best zone of inhibition and concentration of the methanol extract of starfish (Asterias forbesi) on the growth of the fungus Aspergillus sp. and Candida albicans. After doing research on the effectiveness test methanol extract of starfish (Asterias forbesi) on the growth of Candida albicans and Aspergillus sp then found that the methanol extract of Starfish (Asterias forbesi) can inhibit the growth of the fungus Aspergillus sp. and Candida albicans. The methanol extract of starfish capable of inhibiting $100 \%$ the growth of fungi Aspergillus sp. $0.88 \%$ and $0,49 \%$ Candida albicans, the 75\% methanol extract is capable of producing inhibition zone diameter by $0.6 \%$ against the fungus Aspergillus sp and $0.44 \%$ against the fungus Candida albicans. At a concentration of $50 \%$ were able to inhibit the growth of the fungus Aspergillus sp by $0.66 \%$ and 0.42 on the fungus Candida albicans. While the smallest concentration at $25 \%$ inhibition of the ability to produce smaller inhibition $64 \%$ and $0.38 \%$ against the fungus Candida albicans.
\end{abstract}

Keywords: Asterias forbesi, Aspergillus sp. and Candida albicans 


\section{PENDAHULUAN}

Kesehatan merupakan hal yang sangat penting dan berhubungan dengan kehidupan manusia. Kesehatan dipengaruhi oleh kebersihan dan pola hidup yang sehat. Hidup yang sehat bisa diperoleh jika setiap manusia memiliki perilaku yang memperhatikan kesehatan dan semua bisa didapatkan salah satunya dengan cara mengkonsumsi makanan yang sesuai dengan kebutuhan tubuh. Makanan yang kita makan bukan hanya sekedar nikmat, namun juga harus terjaga kualitasnya. Menjaga kebersihan makanan sangat penting bagi kesehatan. Karena pada saat ini banyak penyakit yang menyerang manusia melalui makanan (Maryunanik, 2013 )

Makhfoel (1992) mengatakan bahwa makanan yang kita makan bukan saja harus memenuhi gizi dan mempunyai bentuk yang menarik, tetapi juga harus bersih dan bebas dari mikroorganisme yang dapat menyebabkan penyakit, beberapa penyakit yang ditularkan melalui makanan disebabkan karena adanya jamur patogen.

Berbagai jenis jamur seperti Aspergillus flavus dan Penicillium sp. Sangat banyak menyerang bahan makanan pasca panen, jamur tersebut dapat menghasilkan aflatoksin yang sangat beracun bagi konsumen. Aflatoksin tidak dapat dinetralisir melalui pemasakan sehingga upaya untuk menghindari kontaminasi jamurnya perlu dilakukan (Hutasoit et al., 2013).

Penyakit yang disebabkan oleh jamur masih tetap menjadi masalah kesehatan yang sering dijumpai di rumah sakit Indonesia diantaranya Kandidiasis dan Aspergillosis yang disebabkan oleh jamur Aspergillus dan Candida (Septiadi et al., 2013).

Beraneka ragam obat untuk berbagai macam penyakit bisa diperoleh dengan mudah. Akan tetapi kebanyakan obat-obatan tersebut terbuat dari bahan bahan kimia tertentu. Selain memberikan banyak manfaat, obat-obatan seperti itu pasti memiliki efek samping bagi tubuh (Antika et al., 2013). Penggunaan bahan-bahan kimia sebagai pengendalian pertumbuhan jamur pada bahan pangan dapat menimbulkan dampak yang merugikan bagi manusia. Maka dari itu diperlukan pengendalian secara alami yang tidak menimbulkan dampak yang buruk bagi kesehatan manusia, salah satunya yang dapat digunakan berasal dari laut yaitu bintang laut. Bintang laut merupakan salah satu spesies dari kelas Asteroidaea dan merupakan kelompok dari Echinodermata (Chludil et al., 2000).

Beberapa penelitian tentang senyawa yang terdapat pada bintang laut telah dilakukan. De Marino et al., (1998) mengemukakan bahwa senyawa pada bintang laut family Asteriidae mampu menghasilkan saponin yang dapat digunakan sebagai anti mikroba, ekstrak bintang laut Asterina pectifera aktif terhadap Aspergillus sp dan Cryptococcus neoformans (Choi et al., 1999), bintang laut Anasterias minuta berfungsi sebagai antifungal (Chludil et al., 2000).

Dari hasil penelitian tentang aktifitas Asterias forbesi terhadap bakteri patogen sudah pernah dilakukan oleh (Juariah, 2014) dan menyatakan bahwa ekstrak metanol Asterias forbesi memiliki zat aktif Alkaloida, 
Steroida, Flavonoida dan Saponin yang dapat menghambat pertumbuhan bakteri patogen seperti Staphylococcus aureus, Bacillus subtilis, Pseudomonas aeroginosa, Escherichia coli. penelitian tentang aktifitas Asterias forbesi terhadap jamur belum pernah dilakukan, hal inilah yang mendasari saya melakukan penelitian tentang aktifitas anti jamur spesies Asterias forbesi terhadap Aspergillus sp. dan Candida albicans.

Penelitian ini bertujuan untuk menentukan aktifitas ekstrak metanol bintang laut (Asterias forbesi) terhadap pertumbuhan jamur Aspergillus sp. dan Candida albicans dengan melihat diameter zona hambat yang terbentuk.

\section{TINJAUAN TEORI}

Bintang laut merupakan salah satu spesies dari kelas Asteroidaea, merupakan kelompok Echinodermata. Umumnya Echinodermata berukuran besar, yang terkecil berdiameter $1 \mathrm{~cm}$. Bintang laut mempunyai bentuk seperti bintang pentamerous, kebanyakan spesies mempunyai 5 buah tangan. Beberapa spesies mempunyai tangan kelipatan 5. Diameter rata-rata antara $10-20 \mathrm{~cm}$, terkecil $1 \mathrm{~cm}$, dan terbesar $100 \mathrm{~cm}$. Mulut terletak di pusat pisin (central disk). Seluruh permukaan pisin pusat dan tangan bagian bawah disebut oral, sedangkan bagian bawah disebut aboral. Hewan ini bernafas dengan menggunakan insang kulit, yaitu penonjolan dinding rongga tubuh (selom) yang tipis. Tonjolan ini dilindungi oleh silia dan pediselaria. Dari mulut sampai ujung tangan terdapat lekukan memanjang. Pada tiap lekukan terdapat 2-4 deret kaki tabung. Tepi lekukan terdapat duriduri yang dapat digerakkan untuk melindungi kaki tabung. Pada tiap ujung tangan terdapat tentakel dengan bintik pigmen merah. Anus terdapat di tengah pisin aboral, dimana juga terdapat madreporit (Suwignyo et al., 2005).

\section{METODE PENELITIAN}

\section{Jenis dan Desain Penelitian}

Penelitian ini menggunakan metode eksperimental laboratory secara In Vitro, dengan melihat kemampuan ekstrak metanol Bintang Laut (Asterias forbesi) dalam menghambat pertumbuhan jamur Aspergillus sp. dan Candida albicans.

\section{Waktu Dan Tempat Penelitian}

Penelitian ini dilaksanakan pada bulan Januari sampai April 2016, di Laboratorium Mikrobiologi Akademi Analis Kesehatan Fajar Pekanbaru dan laboraturium Kimia Organik Fakultas Matematika dan Ilmu Pengetahuan Alam Universitas Riau.

\section{Populasi dan Sampel penelitian}

Populasi dalam penelitian ini adalah semua bintang laut (Asterias forbesi) dari perairan Pantai Pulau Poncan Gadang Sibolga Sumatera Utara. Sampel dalam penelitian ini adalah bintang laut Asterias forbesi.

\footnotetext{
Alat dan Bahan

Alat yang digunakan dalam penelitian ini : Erlenmeyer, Freeze dryer, Beaker glass, Petri
} 
dish, Tabung reaksi, Blender, Spatula, Timbangan analitik, Pipet tetes, Jarum ose, Oven, Pinset, Autoclave, Kapas lidi steril, Rotari evaporator, Lampu spiritus, Inkubator, Penggaris.

Bahan yang digunakan ialah Bintang laut (Asterias forbesi) segar yang telah dikeringkan, Strain murni Aspergillus sp. dan Candida albicans,Kontrol (-), Metanol PA (Pro Analisis), Kontrol (+), Disk Nyistatin $2 \%$,media yang digunakan iaalah Potato Dextrose Agar (PDA) sedangkan reagen yang digunakan ialah Alkohol $70 \%, \mathrm{NaCl}$ 0,9 \%, Metanol PA (Pro Analisis), Standar Mc. Forland.

\section{Prosedur Kerja}

Pengeringan Sampel Bintang Laut (Asterias forbesi)

Sampel bintang laut dikeringkan di freeze dryer dengan suhu $-50^{\circ} \mathrm{c}$ selama 48 jam, kemudian dihaluskan menggunakan blender sampai mendapatkan tekstur yang halus dan mudah larut, sehingga proses ekstrasi dapat berjalan dengan maksimal. Bubuk atau tepung bintang laut digunakan dalam proses ekstraksi (Nurullita, 2012).

\section{Ekstraksi Bintang Laut}

Bintang laut sebanyak 100 gram ditimbang, Kemudian maserasi selama 24 jam dengan pelarut metanol, hasil proses maserasi selanjutnya disaring dengan kertas Whatman, kemudian filtrat diuapkan dengan menggunakan alat vakum rotary evaporator untuk menghasilkan ekstrak kental metanol.

\section{Uji Aktivitas Anti Jamur}

\section{Pembuatan Suspensi Jamur}

Ambil 1 ose koloni Aspergillus sp. dan Candida albicans dari strain murni, kemudian disuspensikan kedalam tabung yang berisi $\mathrm{NaCl} \quad 0,9 \%$ fisiologis steril sampai berubah warna keruh sama dengan larutan standar Mc.Forland (Soemarno, 2000).

\section{Penanaman Pada Media Potato Dextrose Agar}

Celupkan kapas lidi steril kedalam $\mathrm{NaCl}$ 0,9\% yang telah ada strain jamur Aspergillus sp. dan Candida albicans, kemudian angkat kapas lidi dengan menekan pada dinding tabung bagian diatas cairan, lalu goreskan pada permukaan media PDA sampai merata, biarkan media Potato Dextrose Agar Plate selama $5-15$ menit agar suspensi jamur meresap kedalam agar (Soemarno, 2000).

\section{Penempelan Disk}

Disk kosong steril masukkan kedalam ekstrak metanol bintang laut pada masing-masing konsentrasi, kemudian letakkan pada permukaan media Potato Dextrose Agar Plate, Ambil kertas Disk Nistatin dan letakkan pada media Potato Dextrose Agar Plate sebagai bahan pembanding (kontrol positif), selanjutnya disk kosong dan celupkan ke metanol, kemudian letakkan pada permukaan media Potato Dextrose Agar plate sebagai bahan pembanding (kontrol negatif), jarak antara disk satu dengan lainnya tidak kurang dari $15 \mathrm{~mm}$. Media yang digunakan dalam penelitian ini sebanyak 3 petri dish, petri dish berisikan 1 disk kontrol positif dan 1 disk 
kontrol negatif dan 1 disk hasil celupkan ekstrak metanol bintang laut (Asterias forbessi, beri tanda label pada masing-masing cawan petri dan diinkubasi 1 x 24 jam pada suhu $37^{\circ} \mathrm{C}$ (Soemarno,2000).

\section{Pembacaan Zona Hambat}

Aktifitas antifungi dapat diketahui dengan cara melakukan pengukuran zona hambat yang terbentuk disekeliling disk yang digunakan pada masing-masing konsentrasi, yakni pada konsentrasi $25 \%, 50 \%, 75 \%, 100 \%$.

\section{Analisis Data}

Data yang telah di peroleh ditabulasikan dalam bentuk tabel dan gambar selanjutnya dilakukan analisis secara deskriptif serta membandingkan dengan berbagai sumber literatur yang yang terkait dengan pembahasan.

\section{HASIL DAN PEMBAHASAN}

\section{Hasil Penelitian}

Setelah dilakukan Penelitian terhadap uji efektifitas ekstrak metanol bintang laut (Asterias forbesi) pada konsentrasi 25\%, 50\%, $75 \%, \quad 100 \%$ dan sebagai kontrol positif menggunakan nystatin, kontrol negatif yaitu metanol PA. dalam menghambat pertumbuhan Aspergillus sp dan Candida albicans secara in vitro yang dilakukan di Laboratorium Mikrobiologi Yayasan Fajar Pekanbaru didapatkan hasil seperti Tabel 1 dan Tabel 2.

Tabel 1. Hasil Uji Efektifitas Ekstrak Metanol Bintang Laut (Asterias forbesi) terhadap Aspergillus sp.

\begin{tabular}{|c|c|c|c|c|c|}
\hline \multirow{2}{*}{$\begin{array}{l}\text { Perlakuan } \\
\text { konsentrasi }\end{array}$} & \multicolumn{3}{|c|}{ Diameter zona hambat (mm) } & \multirow{2}{*}{$\begin{array}{c}\text { Rata-rata } \\
(\mathbf{m m})\end{array}$} & \multirow{2}{*}{$\begin{array}{c}\text { Persentase } \\
(\%)\end{array}$} \\
\hline & Ulangan 1 & Ulangan 2 & Ulangan 3 & & \\
\hline $25 \%$ & 6.5 & 6.6 & 6 & 6.37 & 0.64 \\
\hline $50 \%$ & 6.6 & 6.7 & 6.4 & 6.57 & 0.66 \\
\hline $75 \%$ & 6 & 6 & 6 & 6.00 & 0.60 \\
\hline $100 \%$ & 9 & 9 & 8.5 & 8.83 & 0.88 \\
\hline Nystatin & 10 & 10 & 10 & 10.00 & 100.00 \\
\hline Metanol & 6 & 6 & 6 & 6.00 & - \\
\hline
\end{tabular}

Berdasarkan Tabel 1 terlihat bahwa ekstrak methanol bintang laut mampu menghambat pertumbuhan jamur Aspergilus sp. hal ini ditunjukkan dengan terbentuknya diameter zona hambat pada masing-masing terbesar pada konsentrasi perlakuan $100 \%$ yakni sebesar $0,88 \%$.

Tabel 2. Hasil Uji Efektifitas Ekstrak Metanol Bintang Laut (Asterias forbesi) terhadap Candida albicans.

\begin{tabular}{cccccc}
\hline Perlakuan & \multicolumn{3}{c}{ Diameter zona hambat $(\mathbf{m m})$} & $\begin{array}{c}\text { Rata-rata } \\
(\mathbf{m m})\end{array}$ & $\begin{array}{c}\text { Persentase } \\
\text { konsentrasi }\end{array}$ \\
\cline { 2 - 5 } & Ulangan 1 & Ulangan 2 & Ulangan $\mathbf{3}$ & \\
\hline $\mathbf{2 5 \%}$ & 6 & 6 & 6 & 6.00 & 0.38 \\
$\mathbf{5 0 \%}$ & 7 & 6.5 & 6.5 & 6.67 & 0.42 \\
$\mathbf{7 5 \%}$ & 7 & 7 & 7 & 7.00 & 0.44 \\
$\mathbf{1 0 0 \%}$ & 7.5 & 7.5 & 8.5 & 7.83 & 0.49 \\
Nystatin & 16 & 16 & 16 & 16.00 & 100.00 \\
Metanol & 6 & 6 & 6 & 6.00 & - \\
\hline
\end{tabular}


Dari Tabel 2 diatas terlihat bahwa zona hambat terbesar dihasilkan oleh perlakuan ekstrak bintang laut pada konsentrasi $100 \%$, sebesar $0,49 \%$ dan zona hambat terkecil dihasilkan oleh perlakuan ekstrak methanol $25 \%$ yakni sebesar $0,38 \%$.

Berdasarkan hasil yang telah diperoleh terlihat bahwa ekstrak metanol bintang laut dapat menghambat pertumbuhan jamur Aspergilus sp. dan Candida albicans. kontrol posiitif yang digunakan menghasilkan diameter zona hambat yang lebih besar dibandingkan dengan konsentrasi ekstrak yang digunakan. Dengan menggunakan perbandingan antar hasil yag diperoleh dari masing-masing konsentrasi dengan control maka dihasilkan persentase kemampuan dari ekstrak methanol tersebut dalam menghambat jamur Aspergilus sp. dan Candida albicans.

\section{Pembahasan}

Hasil penelitian yang telah dilakukan dengan menggunakan konsentrasi ekstrak metanol bintang laut yang berbeda terhadap jamur Aspergilus sp. dan Candida albicans menghasilkan diameter yang berbeda-beda. Hal ini karena adanya senyawa yang terkandung dalam ekstrak metanol bintang laut tersebut yang berupa senyawa alkaloid, flavonoid dan saponin. Menurut Juariah (2014), ekstrak bintang laut A. forbesi memiliki komponen bioktif yang berupa alkaloida, triterpenoida/steroida, flavonoida dan saponin yang terdapat pada ekstrak metanol sedangkan pada ekstrak n-heksana dan etil asetat hanya mengandung komponen bioaktif saponin dan triterpenoida/steroida.
Farouk et al., (2007) menyatakan bahwa metabolit sekunder dalam Holothuria scabra yang berpotensi sebagai senyawa antibakteri adalah golongan atau turunan dari senyawa terpenoida, diantaranya saponin, steroida, dan triterpenoida. Golongan senyawa tersebut memiliki polisakarida sehingga dapat menembus membran sel bakteri, sehingga sel tersebut rusak. Konsentrasi suatu bahan yang berfungsi sebagai antimikroba merupakan salah satu faktor penentu besar kecil kemampuannya dalam menghambat pertumbuhan mikroba yang diuji. ekstrak metanol bintang laut mampu menghambat pertumbuhan jamur dengan diameter yang bebeda-beda karena dipengaruhi oleh beberapa hal diantaranya adalah konsentrasi ekstrak yang digunakan, serta kemampuan dari jamur dalam melakukan aktifitas dalam melawan zat atau senyawa yang terkandung dalam ekstrak metanol bintang laut (Asterias forbesi).

\section{KESIMPULAN DAN SARAN}

\section{Kesimpulan}

Setelah dilakukan penelitian dapat disimpulkan bahwa ekstrak metanol bintang laut (Asterias forbesi) mampu menghambat pertumbuhan Aspergillus sp dan Candida albicans. Ekstrak metanol bintang laut 100\% mampu menghambat pertumbuhan jamur Aspergilus sp. sebesar 0,88\% dan Candida albicans sebesar 0,49\%, ekstrak metanol 75\% mampu menghasilkan diameter zona hambat sebesar 0,6\% terhadap jamur Aspergilus sp dan 0,44\% terhadap jamur Candida albicans. Pada 
konsentrasi $50 \%$ mampu menghambat pertumbuhan jamur Aspergilus sp sebesar 0,66\% dan 0,42 pada jamur Candida albicans. sedangkan pada konsentrasi terkecil yakni $25 \%$ menghasilkan kemampuan penghmbatan yang lebih kecil yakni $64 \%$ dan $0,38 \%$ terhadap jamur Candida albicans.

\section{Saran}

Untuk penelitian lebih lanjut disarankan agar melakukan penelitian terhadap ekstrak metanol Bintang laut (Asterias forbesi) terhadap berbagai macam jamur dan parasit dengan metode yang berbeda.

\section{DAFTAR PUSTAKA}

Antika, W., Indriati, G., Irdawati., 2013. Uji Daya Hambat Ekstrak Daun Bunga Tanjung (Mimusops elengi L) Terhadap Pertumbuhan Candida albicans.

Chludil, H., Maiser, M.S dan Seldes, A.M. 2000. Bioactive steroidal glycosides from starfish Anasterias minuta. Molecules 5:352-353.

Choi, D.H., Shin, S. dan I.K., Park. 1999. Characterization of antimicrobial agents extracted from Asterina pectifera. Int. Journal Antimicrob. Agents., 11: 65-68.

De Marino, S., Iorizzi, M., Palagiano, E., Zollo, E., dan Roussakis , C. 1998. Isolation, structure elucidation, and biological activity of the steroid oligoglycosides from an Antarctic starfish of the family Asteriidae. J. Nat. prod., 61 ; 1319-1327
Farouk, A.E., Faizal, A.H.G. dan Ridzwan, B.H. 2007. New Bacterial Species Isolated from Malaysian Sea Cucumbers with Optimized Secreted Antibacterial Activity. J. Am. J. Biochem \& Biotech. 3(2):60-65.

Hutasoit, S., Suada, K., dan Susrama, K., 2013. Uji Aktifitas Anti Jamur Ekstrak Beberapa Jenis Biota Laut Terhadap Aspergillus Flavus dan Penicillium sp. LINK, Jurnal Agroekotegnologi, (2)1 : $\mathrm{Hal}: 28-37$.

Juariah, S.,Suryanto,D., Jamilah, It. 2014. Aktifitas Anti Bakteri Spesies Asterias Forbesi Terhadap Beberapa Jenis Bakteri Patogen. Berkala Perikanan Terubuk Vol 42 No.2 Juli 2014.

Makhfoel. 1992. Toksin Pangan dan Gizi. UGM. Yogyakarta.

Maryunanik. 2013. Perilaku hidup bersih dan sehat (PHBS). Trans Info Media. Jakarta Notoatmodjo, S. 2005. Metodologi Penelitian Kesehatan. Rineka Cipta. Jakarta.

Nurullita, H.P. 2012. Kdanungan Komponen Bioaktif dan Aktivitas Antimikroba Ekstrak Bintang Laut Culcita schmideliana. Skripsi. Fakultas Perikanan dan Ilmu Kelautan Institut Pertanian Bogor.

Septiadi, T., Pringgenies, D., Radjasa O., 2013. Uji Fitokimia Dan Antijamur Ekstrak Teripang Keling (Holoturia atra) Dari Pantai Bandengan Jepara Terhadap Jamur Candida albicans, Jurnal Of Marine Research, (2)2 : Hal : 77-80 